\title{
The role of epithelial malfunction in the pathogenesis of enteropathogenic E. coli-induced diarrhea
}

\author{
Tamia K Lapointe, Pamela M O'Connor and Andre G Buret
}

The homeostatic balance of the gastrointestinal tract relies on a single layer of epithelial cells, which assumes both digestive and protective functions. Enteric pathogens, including enteropathogenic Escherichia coli (EPEC), have evolved numerous mechanisms to disrupt basic intestinal epithelial functions, promoting the development of gastrointestinal disorders. Despite its non-invasive nature, EPEC inflicts severe damage to the intestinal mucosa, including the dysregulation of water and solute transport and the disruption of epithelial barrier structure and function. Despite the high prevalence and morbidity of disease caused by EPEC infections, the etiology of its pathogenesis remains incompletely understood. This review integrates the newest findings on EPEC-epithelial interactions with established mechanisms of disease in an attempt to give a comprehensive understanding of the cellular processes whereby this common pathogen may cause diarrheal illness.

Laboratory Investigation (2009) 89, 964-970; doi:10.1038/labinvest.2009.69; published online 20 July 2009

KEYWORDS: apical junctional complexes; EPEC; epithelial barrier; host inflammatory responses; intestinal permeability; ion and water transport

Escherichia coli (E. coli) is the most abundant facultative anaerobe in the normal microflora of the mammalian colon. ${ }^{1}$ In physiological situations, this close interaction is mutually beneficial to both the bacteria and the host; however, certain strains of E. coli such as enteropathogenic E. coli (EPEC) have acquired virulence genetic islands and small gene clusters that contribute to the development of acute gastroenteritis. In developing countries, EPEC is a significant cause of infantile diarrhea, which is associated with a high rate of mortality $(10-40 \%)^{2}$ In the last decade, identification and characterization of several EPEC virulence factors have significantly contributed to our understanding of EPEC pathogenesis, especially with regard to their effects on basic intestinal epithelial functions. Nevertheless, the complete mechanism underlying EPEC-induced diarrheal illness remains elusive. The following paragraphs offer a state-of-the-art review of the mechanisms by which EPEC mediates epithelial dysfunction, and provides novel insights into molecular events whereby this common pathogen may induce diarrheal illness.

\section{ATTACHING AND EFFACING LESIONS}

Enteropathogenic E. coli is an extracellular non-invasive Gram-negative bacterium. Its virulence relies on a specific chromosomal region called the locus of enterocyte effacement (LEE), which allows the bacteria to form attaching and effacing (A/E) lesions at the surface of the intestinal mucosa. ${ }^{3}$ The formation of A/E lesions begins with the localized adhesion of EPEC to intestinal epithelial cells (IECs), which is achieved by the expression of bundle-forming pili encoded by the EPEC adherence factor plasmid (EAF). ${ }^{4}$ In fact, deletion of this plasmid abolishes the development of EPEC-induced diarrhea, further supporting its requirement for the pathophysiological process. ${ }^{5}$ The locus of enterocyte effacement encodes a type 3 secretion system (T3SS), which is used to inject bacterial factors such as the translocated intimin receptor (Tir) into host cells. ${ }^{6,7}$ Once inside IECs, Tir is inserted into the plasma membrane where it binds the EPEC outer membrane adhesin intimin. ${ }^{7}$ The cytoplasmic domain of Tir also interacts with the adaptor protein Nck and signaling molecules N-WASP and Arp2/3, resulting in remodeling of the actin cytoskeleton and the formation of a pedestal complex beneath attached bacteria. ${ }^{8-10}$ In addition to actin filaments, several structural proteins are recruited to the site of bacterial attachment, including $\alpha$-actinin, ezrin, and myosin light chain II (MLC), which contributes to pedestal formation. ${ }^{11-13}$ 
The T3SS also mediates the translocation of several E. colisecreted proteins (Esp), which act to subvert multiple epithelial cell signaling pathways, contributing to disease initiation and persistence. The EPEC locus of enterocyte effacement-encoded effector molecules involved in diarrhea are listed in Table 1, and will be discussed in further detail with regard to their effect on the intestinal epithelium in the following sections.

\section{EPEC-INDUCED DIARRHEA: ALTERATIONS TO EPITHELIAL FUNCTION}

During EPEC infection, a variety of mechanisms contribute to the dysregulation of intestinal architecture, ion and water transport, epithelial barrier structure and function, and host inflammatory responses, all contributing to disease establishment. The following paragraphs elaborate on cellular and molecular events involved in the pathophysiology of EPEC-induced diarrhea.

\section{Loss of Absorptive Surface}

Epithelial microvilli significantly increase the absorptive surface of the intestine, and contain a broad array of functional elements, including digestive enzymes and electrolyte/ nutrient transporters. During EPEC infection, the cytoskeletal rearrangement required for pedestal formation results in microvilli destruction and diffuse shortening. These changes severely diminish the absorptive capacity of the affected area, enhancing the osmotic load of the luminal contents, and driving loss of water and consequent diarrhea. ${ }^{14,15}$ However, EPEC-induced diarrheal symptoms occur before the full formation of $\mathrm{A} / \mathrm{E}$ lesions. ${ }^{16}$ Therefore, although the formation of $\mathrm{A} / \mathrm{E}$ lesions and the diffuse loss of brush border surface area certainly exacerbate diarrhea, they are unlikely to be the leading mechanisms in its initiation. Instead, a more active secretory mechanism is suspected to mediate the rapid development of initial diarrheal symptoms.

\section{Ion and Water Transport}

The intestinal epithelium has evolved elaborate mechanisms to maximize its fluid and electrolyte absorption, such that from the 8-9 lof fluid entering the human gut daily, only $100-200 \mathrm{ml}$ are ultimately lost in the feces. ${ }^{17}$ The ionic balance on either side of the intestinal epithelium is regulated by various channels and transporters (reviewed by Barrett and Keely ${ }^{18}$ ). Water and solute absorption is mainly achieved by $\mathrm{Na}^{+} /$glucose (SGLT-1), $\mathrm{Na}^{+} / \mathrm{H}^{+}$(NHE2-3) and $\mathrm{Cl}^{-} / \mathrm{HCO}_{3}^{-}$ (DRA/PAT1) exchangers. On the other hand, the apical cAMP-dependent cystic fibrosis transmembrane conductance regulator (CFTR) contributes to the creation of an osmotic gradient that drives the movement of water into the lumen. ${ }^{18}$ These transport pathways are tightly controlled, and their dysregulation is believed to account for the early-onset of EPEC-induced watery diarrhea, as discussed below.
Table 1 EPEC LEE-encoded effector molecules involved in the development of diarrhea

\begin{tabular}{|c|c|c|}
\hline & $\begin{array}{l}\text { Effect on the intestinal } \\
\text { epithelium }\end{array}$ & Reference \\
\hline \multirow[t]{6}{*}{ Tir } & A/E lesion & \\
\hline & Intimate attachment & Kenny et $a l^{P}$ \\
\hline & Cytoskeletal & Gruenheid et $\mathrm{al}_{1}^{8} \mathrm{Ka}$ \\
\hline & rearrangement & et $a l_{1}^{9}$ Schuller et al \\
\hline & Ion and water transport & \\
\hline & SGLT-1 inactivation & Gill et $a l^{29}$ \\
\hline \multirow[t]{5}{*}{ Map } & Ion and water transport & \\
\hline & SGLT-1 inactivation & Gill et $a^{29}$ \\
\hline & Epithelial barrier & \\
\hline & Claudin-1, -3 and -5 & Muza-Moons et al ${ }^{50}$ \\
\hline & internalization & \\
\hline \multirow[t]{4}{*}{ EspB } & Epithelial barrier & \\
\hline & Ezrin and ZO- 1 redistribution & Crane et $a l^{53}$ \\
\hline & Association of $\mathrm{PKC} \alpha$ with & Nougayrede and \\
\hline & $\begin{array}{l}\text { E-cadherin and redistribu- } \\
\text { tion of } \beta \text {-catenin }\end{array}$ & Donnenberg $^{54}$ \\
\hline
\end{tabular}

\begin{tabular}{|c|c|c|}
\hline EspF & Ion and water transport & \\
\hline & Reduction of NHE3 & Hecht and Koutsouris, ${ }^{21}$ \\
\hline & expression & Hoyle and Burnstock ${ }^{22}$ \\
\hline & $\mathrm{AQP}$ redistribution & Collins et $a 1^{28}$ \\
\hline & SGLT-1 inactivation & Gill et $\left.a\right|^{29}$ \\
\hline & Epithelial barrier & \\
\hline & Claudin-1, $-3,-5$, occludin, & Ma et $a l_{,}^{45}$ Elliott et $a l_{,}^{46}$ \\
\hline & ZO-1, and ezrin & Berryman et al, ${ }^{47}$ \\
\hline & redistribution & Simonovic et al, ${ }_{1}^{48}$ \\
\hline & & Malladi et $a l_{,}^{49}$ \\
\hline & & Crane et $a f^{33}$ \\
\hline
\end{tabular}

EspG EspG2 Ion and water transport
Destruction of the micro- Hodges et al
tubule network, alteration of
DRA embrane targeting, and
reduction of $\mathrm{Cl}^{-} / \mathrm{HCO}_{3}^{-}$
exchange

AQP redistribution Collins et $a^{28}$

\section{Direct modulation of ion transport}

Enteropathogenic E. coli is able to modulate host cell electrolyte transport. A study carried out on colonic epithelial 
Caco-2 cells showed that EPEC-secreted proteins, EspA, $\mathrm{EspB}$, and EspD, induce a rapid and transient increase in short circuit current (Isc), partially attributed to $\mathrm{Cl}^{-}$secretion. ${ }^{19,20}$ Nevertheless, a report published the following year failed to show a similar response in intestinal epithelial T84 cells, but found that EPEC decreases Isc in response to $\mathrm{Ca}^{2+}$. and cAMP-dependent secretagogues, in a $\mathrm{Cl}^{-}$-independent manner. ${ }^{21}$ The differing outcomes of these experiments could potentially be explained by the absorptive versus secretory phenotypes of the epithelial cell lines used in each model of infection. Furthermore, in physiological conditions, the presence of an important array of mediators released by several cell populations also influence the ion transport activity during EPEC infection. For example, galanin, a neuropeptide controlling intestinal motility, ${ }^{22}$ has been found to modulate $\mathrm{Cl}^{-}$secretion during enteric infections. Upon EPEC infection, the expression of the galanin receptor (GAL-1R) is significantly increased in vitro and in vivo in a NF- $\kappa \mathrm{B}$-dependent manner. ${ }^{23}$ Gal-1R activation then mediates $\mathrm{Ca}^{2+}$-dependent $\mathrm{Cl}^{-}$secretion, implying that neuronal regulation of $\mathrm{Cl}^{-}$secretion contributes to the excessive luminal fluid accumulation observed during EPEC-induced diarrhea. ${ }^{24}$

Enteropathogenic E. coli infection also affects $\mathrm{Na}^{+}$ transport. Indeed, EPEC infection reduces the expression of NHE3 in Caco-2 cells in an EspF-dependent manner. ${ }^{25,26}$ NHE3 is the dominant isoform of NHE contributing to small intestinal $\mathrm{Na}^{+}$absorption and mice deficient in this transporter experience severe diarrhea. ${ }^{27}$ Importantly, in vivo experiments showed that the relative contribution of NHE3 to overall $\mathrm{Na}^{+}$absorption is much higher $(4 \times)$ in post-weaning rats than adult rats. ${ }^{28}$ It is still unclear if this trend is representative of what happens during human development, but if so, it could partly explain the increased susceptibility of young children to EPEC.

Enteropathogenic E. coli is also known to reduce $\mathrm{Cl}^{-} / \mathrm{HCO}_{3}^{-}$exchange in vitro and in vivo. ${ }^{29}$ This effect appears to be mediated by EspG- and EspG2-dependent disruption of the microtubular network. ${ }^{29}$ EPEC-induced microtubule dysfunction alters the membrane targeting of the $\mathrm{Cl}^{-} / \mathrm{HCO}_{3}^{-}$exchanger DRA, resulting in reduced $\mathrm{Cl}^{-}$uptake and its accumulation in the lumen, driving water loss. ${ }^{29}$ These results have recently been corroborated by a study showing an important downregulation of DRA mRNA in mice challenged with Citrobacter rodentium, a natural mouse pathogen used as an animal model of EPEC infection. $^{30}$

Furthermore, EPEC virulence factors, EspF, Map, Tir, and intimin, have been shown to act together to rapidly inactivate SGLT-1, a cotransporter responsible for about $70 \%$ of the total fluid uptake in the small intestine. ${ }^{31,32}$ It remains to be established whether this mechanism contributes to the refractory response to oral rehydration therapy in patients with severe diarrhea. ${ }^{33,34}$
Taken together, these studies suggest that, unlike other diarrheagenic pathogens, such as Vibrio cholera, that promote active enterocyte $\mathrm{Cl}^{-}$secretion, ${ }^{17}$ EPEC creates an imbalance in the electroneutral $\mathrm{Na}^{+} / \mathrm{Cl}^{-}$exchange across the plasma membrane, which reduces water absorption and contributes to the establishment of diarrhea.

\section{Water transport}

Enteropathogenic E. coli also directly alters water transport, independently of ion distribution, by modulating epithelial aquaporin $(\mathrm{AQP})$ expression. AQPs are water and water/ glycerol channels expressed in colonic epithelial cells allowing water absorption through cellular membranes. ${ }^{35} \mathrm{AQP} 2$ and AQP3 are expressed in the lateral and apical membranes of murine colonocytes, specifically in the distal colon. ${ }^{36}$ During challenge with $C$. rodentium, the development of diarrhea correlates with the disruption of this normal pattern of $A Q P$ expression. ${ }^{36}$ Despite no significant changes in their total expression, AQP2 and AQP3 were shown to translocate from the membrane into the cytosolic compartment. These effects were mediated, at least in part, by EspF and EspG, while $\mathrm{EspH}$ and the mitochondria-associated protein (Map) were not involved. ${ }^{36}$ Interestingly, after recovery from the infection, mice displayed a normal pattern of AQP distribution. More recently, a comparative study of genome-wide transcriptional changes during $C$. rodentium infection also showed a drastic downregulation of AQP8 in infected mice. ${ }^{30}$

Together, these studies indicate that a reduction of luminal water absorption, in addition to the decrease in solute uptake described earlier, contributes to EPEC-mediated watery diarrhea.

\section{Epithelial Barrier Function}

The intestinal epithelium acts as a physical barrier separating the luminal environment and subepithelial tissues. This polarized barrier is primarily maintained by apical junctional complexes, including tight junctions and adherens junctions, which connect neighboring epithelial cells (reviewed by Harhaj and Antonetti ${ }^{37}$ and Niessen ${ }^{38}$ ). Tight junctions are made of complex interactions between up to 40 proteins including the transmembrane proteins occludin, junctional adhesion molecule, and claudins. These proteins are anchored to the actin filaments and MLC of the perijunctional actinomyosin ring through cytosolic plaque proteins of the zonula occludens ( $\mathrm{ZO})$ family. Adherens junctions, which lie basolateral to the tight junctions, are formed by the interaction of the transmembrane protein E-cadherin with cytoplasmic proteins of the catenin family.

\section{Disruption of epithelial barrier structure and function}

It is now well established that EPEC alters both the structure and function of the epithelial barrier. Apical junctional complexes are dynamic complexes and their permeability is regulated by several mechanisms, one of which is the phosphorylation of MLC by MLC kinase. EPEC is known to 
activate MLC kinase, which induces the contraction of the actinomyosin ring and the consequent distention of transmembrane tight junctional proteins, resulting in an increase in paracellular permeability. ${ }^{13,39}$

Enteropathogenic E. coli can also directly alter tight junctional proteins. Indeed, EPEC infection induces redistribution of occludin, which results in a significant decrease in barrier function both in vitro and in vivo, in an EspF-dependent manner. ${ }^{40-43}$ Redistribution of ZO-1, cytoplasmic clearing of claudin-1, and a gradual decrease in protein-protein interaction within the tight junctions have also been reported during EPEC infection. ${ }^{41}$ Finally, EspF and Map have been shown to induce cytosolic translocation of claudin-1, -3 , and -5 in C. rodentium-infected mice. ${ }^{44,45}$ This mechanism requires the locus of enterocyte effacementencoded EspF chaperone, CesF, for the translocation of EspF into the host cytosol and the subsequent reduction of TER. ${ }^{46}$

Ezrin is concentrated in the microvilli of IECs and plays an important role in modulating tight junction structure and function, as it links tight junctional proteins to the actin cytoskeleton. ${ }^{47}$ Upon EPEC infection, ezrin is relocalized to the pedestal, where it gets phosphorylated and activated. ${ }^{48}$ This effect is EspB and EspF dependent, and results in the redistribution of ZO- 1 and a subsequent decrease in TER. ${ }^{48}$

The adherens junctions do not escape the disruptive effects of EPEC. EspB-mediated phosphorylation and subsequent activation of PKC $\alpha$ have been reported during EPEC infection, increasing its association with the transmembrane protein E-cadherin. ${ }^{49}$ This results in the cytoplasmic redistribution of $\beta$-catenin and an increase in paracellular permeability. ${ }^{49}$

Enteropathogenic E. coli-induced disruption of epithelial apical junctional complexes causes a loss of polarity in epithelial cells. Upon EPEC infection, basolateral $\beta_{1}$-integrin moves to the apical side of enterocytes where it can interact with intimin..$^{50}$ Although Tir remains essential for bacterial attachment, cytoskeletal rearrangement, and barrier defects, the interaction of $\beta_{1}$-integrin with intimin further enhances the attachment of EPEC to IECs and is required for maximal decreases in TER. ${ }^{50}$

It should be noted that certain gastrointestinal pathogens, such as the parasite Giardia lambia, are known to modulate epithelial permeability through the induction of apoptosis. $^{51,52}$ As mentioned before, EPEC induces apoptosis in infected IECs in a caspase-dependent manner. ${ }^{53,54}$ Nevertheless, recent studies concluded that the increase in epithelial permeability caused by EPEC is caspase-independent, as the inhibition of different initiator and executioner caspases did not restore the epithelial barrier properties. ${ }^{55,56}$

Importantly, all the above mechanisms by which EPEC modulates the integrity of epithelial barrier structure and function result in an electrochemical gradient imbalance across the epithelium, altering water and ion distribution, thereby contributing to the establishment of diarrhea. These processes are illustrated in Figure 1.

\section{Intestinal Inflammation}

Enteropathogenic E. coli possesses several pathogen-associated molecular patterns recognized by Toll-like receptors (TLR) at the surface of enterocytes and immune cells. Although earlier findings have suggested that EPEC attachment to IECs is required for the initiation of an inflammatory response, ${ }^{57}$ recent evidence indicates that EPEC flagellin, but not EPEC LPS, is able to activate the mucosal immune system through the epithelial TLR5 activation. ${ }^{58,59}$ Furthermore, it appears that the EPEC-mediated inflammatory response is the net result of the activation of both pro- and anti-inflammatory signaling pathways in host cells. Indeed, it was shown that EPEC-secreted components exert a proinflammatory effect, whereas its attachment to IECs and the translocation of effector molecules by the T3SS attenuate this response. ${ }^{60}$ The outcome of this balance is the induction of an inflammatory response, mostly driven by the activation of $\mathrm{NF}-\kappa \mathrm{B}, \mathrm{MAPK}-\mathrm{ERK} 1 / 2$, and protein kinase $\mathrm{C} \zeta$, all leading to the expression and release of interleukin (IL)-8, a potent neutrophil chemoattractant. ${ }^{58,61,62}$ This results in an important neutrophilic infiltration into the lamina propria, epithelial crypts, and intestinal lumen. ${ }^{57}$

The onset of diarrhea during EPEC infection occurs within a few hours of colonization and before the full engagement of the mucosal innate immune system, suggesting that the inflammatory response directed against EPEC is not the initiating factor in the development of diarrhea. ${ }^{63}$ Nevertheless, inflammatory processes could certainly be involved in disease duration and severity, as discussed below.

Neutrophils infiltrating the infected mucosa upon EPEC infection release important amounts of $5^{\prime} \mathrm{AMP}^{64}$ At the apical surface of IECs, $5^{\prime}$ ectonucleotidase (CD73) converts $5^{\prime}$ AMP into adenosine. Adenosine then interacts in a paracrine manner with the $\mathrm{A} 2 \mathrm{~b}$ adenosine receptor, which by its association with G-protein $\alpha$ s, indirectly activates adenylyl cyclase. ${ }^{64,65}$ The subsequent increase in cAMP results in the activation of PKA and CFTR, promoting $\mathrm{Cl}^{-}$secretion and enhancing luminal movement of water. ${ }^{64,65}$ In addition, another study showed that EPEC is able to induce the cellular release and rapid breakdown of ATP into adenine nucleotides and adenosine, feeding into the earlier described signaling cascade. $^{66}$

The inflammatory response associated with EPEC is associated with an increase in proinflammatory cytokines, such as TNF $\alpha$, interferon (IFN) $\gamma$, and IL- $1 \beta$, in the infected mucosa. $^{58,60}$ Several studies have shown the role of these cytokines in epithelial barrier disruption. Indeed, IFN $\gamma$, alone or in synergy with $\mathrm{TNF} \alpha$, is known to induce epithelial barrier dysfunction, independently of its proapoptotic properties. ${ }^{67-69}$ Furthermore, a recent study has shown the ability of IL- $1 \beta$ to alter epithelial tight junction permeability in an NF- $\kappa \mathrm{B}-$ dependent manner. ${ }^{70}$ Further studies investigated the hypothesis that, during EPEC infection, such proinflammatory mediators may contribute to epithelial barrier damage and diarrhea. In $C$. rodentium-infected mice, tight junction 


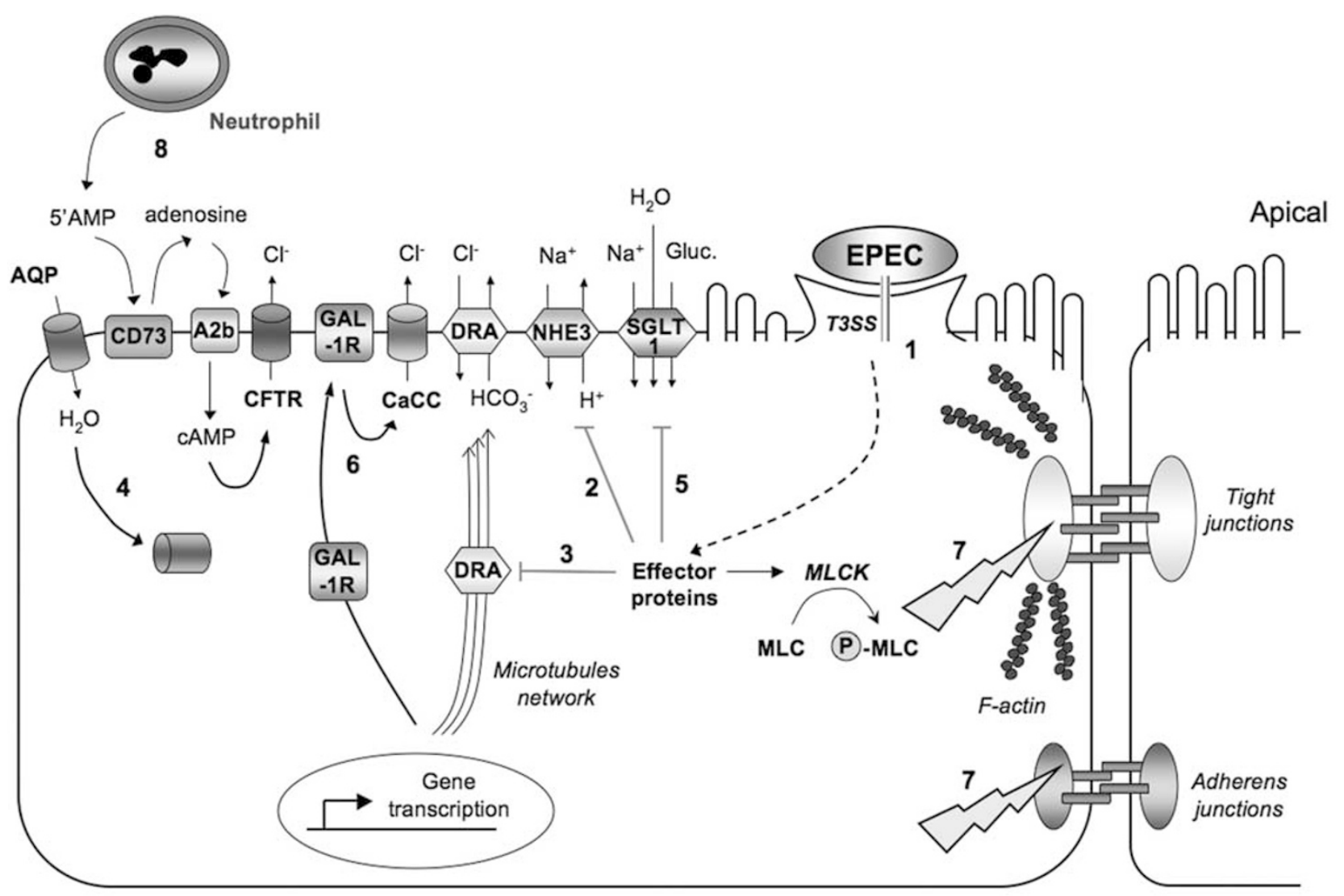

Basolateral

Figure 1 Epithelial mechanisms involved in EPEC-induced watery diarrhea. (1) Formation of A/E lesions and microvilli effacement leads to loss of absorptive surface. (2) Inhibition of NHE3 reduces $\mathrm{Na}^{+}$absorption. (3) Inhibition of DRA translocation to the apical membrane reduces $\mathrm{Cl}^{-}$uptake. (4 and 5) Membrane-to-cytosol translocation of AQP and inhibition of SGLT-1 promote luminal accumulation of water. (6) Galanin/GAL-1R-mediated Ca ${ }^{2+}$-dependent $\mathrm{Cl}^{-}$secretion. (7) Disruption of apical junctional complexes increases paracellular permeability. (8) Neutrophil release of $5^{\prime}$ AMP activates A2b and CFTR in a cAMP-dependent manner.

disruption occurred before inflammation was detected. ${ }^{71}$ Furthermore, 21 days post-infection, when the host had cleared the pathogen, inflammation was sustained, but the structure of the tight junctions appeared intact. These findings suggest that while the generation of proinflammatory cytokines could contribute to the duration and severity of disease, it is not the instigating event in EPEC-mediated barrier dysfunction and consequent diarrhea.

\section{CONCLUSION}

The multifactorial effect of EPEC on the intestinal epithelium certainly contributes to the complexity of its pathogenesis; however, the discovery of several virulence factors and the signaling cascades they engage has considerably enhanced our understanding of the mechanisms by which EPEC mediates diarrheal illness in humans. Although the modulation of electrolyte and water transport appears to be responsible for the early-onset of diarrhea, disruption of the intestinal epithelial barrier, cytoskeletal rearrangements, loss of absorptive surface, and activation of the mucosal innate immune system further amplify the outcome of infection (summarized in Figure 1).

\section{ACKNOWLEDGEMENTS}

A part of the work discussed in this article was funded by the Natural Sciences and Engineering Research Council of Canada. TK Lapointe and PM O'Connor are recipients of studentships from the Alberta Heritage Foundation for Medical Research.

\section{DISCLOSURE/CONFLICT OF INTEREST}

The authors declare no conflict of interest.

1. Kaper JB, Nataro JP, Mobley HL. Pathogenic Escherichia coli. Nat Rev Microbiol 2004;2:123-140.

2. Spears KJ, Roe AJ, Gally DL. A comparison of enteropathogenic and enterohaemorrhagic Escherichia coli pathogenesis. FEMS Microbiol Lett 2006;255:187-202.

3. McDaniel TK, Jarvis KG, Donnenberg MS, et al. A genetic locus of enterocyte effacement conserved among diverse enterobacterial pathogens. Proc Natl Acad Sci USA 1995;92:1664-1668.

4. Giron JA, Ho AS, Schoolnik GK. An inducible bundle-forming pilus of enteropathogenic Escherichia coli. Science 1991;254:710-713.

5. Levine MM, Nataro JP, Karch $\mathrm{H}$, et al. The diarrheal response of humans to some classic serotypes of enteropathogenic Escherichia coli is dependent on a plasmid encoding an enteroadhesiveness factor. $J$ Infect Dis 1985;152:550-559.

6. Jarvis $K G$, Giron JA, Jerse $A E$, et al. Enteropathogenic Escherichia coli contains a putative type III secretion system necessary for the export 
of proteins involved in attaching and effacing lesion formation. Proc Natl Acad Sci USA 1995;92:7996-8000.

7. Kenny B, DeVinney $\mathrm{R}$, Stein $\mathrm{M}$, et al. Enteropathogenic E. coli (EPEC) transfers its receptor for intimate adherence into mammalian cells. Cell 1997:91:511-520.

8. Gruenheid S, DeVinney R, Bladt F, et al. Enteropathogenic E. coli Tir binds Nck to initiate actin pedestal formation in host cells. Nat Cell Biol 2001;3:856-859.

9. Kalman D, Weiner OD, Goosney DL, et al. Enteropathogenic E. coli acts through WASP and Arp2/3 complex to form actin pedestals. Nat Cell Biol 1999;1:389-391.

10. Schuller S, Chong Y, Lewin J, et al. Tir phosphorylation and Nck/N-WASP recruitment by enteropathogenic and enterohaemorrhagic Escherichia coli during ex vivo colonization of human intestinal mucosa is different to cell culture models. Cell Microbiol 2007:9:1352-1364.

11. Goosney DL, DeVinney R, Finlay BB. Recruitment of cytoskeletal and signaling proteins to enteropathogenic and enterohemorrhagic Escherichia coli pedestals. Infect Immun 2001;69:3315-3322.

12. Goosney DL, DeVinney R, Pfuetzner RA, et al. Enteropathogenic E. coli translocated intimin receptor, Tir, interacts directly with alpha-actinin. Curr Biol 2000;10:735-738.

13. Manjarrez-Hernandez HA, Baldwin TJ, Williams $\mathrm{PH}$, et al. Phosphorylation of myosin light chain at distinct sites and its association with the cytoskeleton during enteropathogenic Escherichia coli infection. Infect Immun 1996;64:2368-2370.

14. Buret A, Olson ME, Gall DG, et al. Effects of orally administered epidermal growth factor on enteropathogenic Escherichia coli infection in rabbits. Infect Immun 1998;66:4917-4923.

15. Goosney DL, Gruenheid S, Finlay BB. Gut feelings: Enteropathogenic E. coli (EPEC) interactions with the host. Annu Rev Cell Dev Biol 2000;16:173-189.

16. Donnenberg MS, Tacket CO, James SP, et al. Role of the eaeA gene in experimental enteropathogenic Escherichia coli infection. J Clin Invest 1993;92:1412-1417.

17. Berkes J, Viswanathan VK, Savkovic SD, et al. Intestinal epithelial responses to enteric pathogens: effects on the tight junction barrier, ion transport, and inflammation. Gut 2003;52:439-451.

18. Barrett K, Keely S. Integrative physiology and pathology of intestinal electrolyte transport. In: Johnson LR (ed). Physiology of the Gasrointestinal Tract, Volume 2. 4th edn Academinc Press, Elsevier, 2006. pp 1931-1951.

19. Collington GK, Booth IW, Donnenberg MS, et al. Enteropathogenic Escherichia coli virulence genes encoding secreted signalling proteins are essential for modulation of Caco-2 cell electrolyte transport. Infect Immun 1998;66:6049-6053.

20. Collington GK, Booth IW, Knutton S. Rapid modulation of electrolyte transport in Caco-2 cell monolayers by enteropathogenic Escherichia coli (EPEC) infection. Gut 1998;42:200-207.

21. Hecht G, Koutsouris A. Enteropathogenic E. coli attenuates secretagogue-induced net intestinal ion transport but not Cl- secretion. Am J Physiol 1999;276:G781-G788.

22. Hoyle $\mathrm{CH}$, Burnstock $\mathrm{G}$. Galanin-like immunoreactivity in enteric neurons of the human colon. J Anat 1989;166:23-33.

23. Hecht G, Marrero JA, Danilkovich A, et al. Pathogenic Escherichia coli increase $\mathrm{Cl}$ - secretion from intestinal epithelia by upregulating galanin1 receptor expression. J Clin Invest 1999;104:253-262.

24. Benya RV, Marrero JA, Ostrovskiy DA, et al. Human colonic epithelial cells express galanin-1 receptors, which when activated cause $\mathrm{Cl}$ secretion. Am J Physiol 1999;276:G64-G72.

25. Hecht G, Hodges K, Gill RK, et al. Differential regulation of $\mathrm{Na}+/ \mathrm{H}+$ exchange isoform activities by enteropathogenic $E$. coli in human intestinal epithelial cells. Am J Physiol Gastrointest Liver Physiol 2004;287:G370-G378.

26. Hodges K, Alto NM, Ramaswamy K, et al. The enteropathogenic E. coli effector protein EspF decreases sodium hydrogen exchanger 3 activity. Cell Microbiol 2008;21:21.

27. Gawenis LR, Stien X, Shull GE, et al. Intestinal NaCl transport in NHE2 and NHE3 knockout mice. Am J Physiol Gastrointest Liver Physiol 2002;282:G776-G784.

28. Collins JF, Xu H, Kiela PR, et al. Functional and molecular characterization of NHE3 expression during ontogeny in rat jejunal epithelium. Am J Physiol 1997;273:C1937-C1946.
29. Gill RK, Borthakur A, Hodges K, et al. Mechanism underlying inhibition of intestinal apical $\mathrm{Cl} / \mathrm{OH}$ exchange following infection with enteropathogenic $E$. coli. J Clin Invest 2007;117:428-437.

30. Borenshtein D, Fry RC, Groff EB, et al. Diarrhea as a cause of mortality in a mouse model of infectious colitis. Genome Biol 2008;9:R122.

31. Dean $\mathrm{P}$, Maresca $M$, Schuller $S$, et al. Potent diarrheagenic mechanism mediated by the cooperative action of three enteropathogenic Escherichia coli-injected effector proteins. Proc Natl Acad Sci USA 2006;103:1876-1881.

32. Meinild A, Klaerke DA, Loo DD, et al. The human Na+-glucose cotransporter is a molecular water pump. J Physiol 1998;508 (Part 1):15-21.

33. Casburn-Jones AC, Farthing MJ. Management of infectious diarrhoea. Gut 2004;53:296-305.

34. Nataro JP, Kaper JB. Diarrheagenic Escherichia coli. Clin Microbiol Rev 1998;11:142-201.

35. Agre $P$, King LS, Yasui $M$, et al. Aquaporin water channels-from atomic structure to clinical medicine. J Physiol 2002;542:3-16.

36. Guttman JA, Samji FN, Li Y, et al. Aquaporins contribute to diarrhoea caused by attaching and effacing bacterial pathogens. Cell Microbiol 2007;9:131-141.

37. Harhaj NS, Antonetti DA. Regulation of tight junctions and loss of barrier function in pathophysiology. Int J Biochem Cell Biol 2004;36:1206-1237.

38. Niessen CM. Tight junctions/adherens junctions: Basic structure and function. J Invest Dermatol 2007;127:2525-2532.

39. Turner JR, Rill BK, Carlson SL, et al. Physiological regulation of epithelial tight junctions is associated with myosin light-chain phosphorylation. Am J Physiol 1997;273:C1378-C1385.

40. McNamara BP, Koutsouris A, O'Connell CB, et al. Translocated EspF protein from enteropathogenic Escherichia coli disrupts host intestinal barrier function. J Clin Invest 2001;107:621-629.

41. Muza-Moons MM, Schneeberger EE, Hecht GA. Enteropathogenic Escherichia coli infection leads to appearance of aberrant tight junctions strands in the lateral membrane of intestinal epithelial cells. Cell Microbiol 2004;6:783-793.

42. Shifflett DE, Clayburgh DR, Koutsouris A, et al. Enteropathogenic E. coli disrupts tight junction barrier function and structure in vivo. Lab Invest 2005;85:1308-1324.

43. Simonovic I, Rosenberg J, Koutsouris A, et al. Enteropathogenic Escherichia coli dephosphorylates and dissociates occludin from intestinal epithelial tight junctions. Cell Microbiol 2000;2:305-315.

44. Guttman JA, Li Y, Wickham ME, et al. Attaching and effacing pathogeninduced tight junction disruption in vivo. Cell Microbiol 2006;8: 634-645.

45. Ma C, Wickham ME, Guttman JA, et al. Citrobacter rodentium infection causes both mitochondrial dysfunction and intestinal epithelial barrier disruption in vivo: role of mitochondrial associated protein (Map). Cell Microbiol 2006;8:1669-1686.

46. Elliott $S J, O^{\prime}$ Connell $C B$, Koutsouris $A$, et al. A gene from the locus of enterocyte effacement that is required for enteropathogenic Escherichia coli to increase tight-junction permeability encodes a chaperone for EspF. Infect Immun 2002;70:2271-2277.

47. Berryman M, Franck Z, Bretscher A. Ezrin is concentrated in the apical microvilli of a wide variety of epithelial cells whereas moesin is found primarily in endothelial cells. J Cell Sci 1993;105(Part 4):1025-1043.

48. Simonovic I, Arpin M, Koutsouris A, et al. Enteropathogenic Escherichia coli activates ezrin, which participates in disruption of tight junction barrier function. Infect Immun 2001;69:5679-5688.

49. Malladi V, Puthenedam M, Williams PH, et al. Enteropathogenic Escherichia coli outer membrane proteins induce iNOS by activation of NF-kappaB and MAP kinases. Inflammation 2004;28:345-353.

50. Muza-Moons MM, Koutsouris A, Hecht G. Disruption of cell polarity by enteropathogenic Escherichia coli enables basolateral membrane proteins to migrate apically and to potentiate physiological consequences. Infect Immun 2003;71:7069-7078.

51. Chin AC, Teoh DA, Scott KG, et al. Strain-dependent induction of enterocyte apoptosis by Giardia lamblia disrupts epithelial barrier function in a caspase-3-dependent manner. Infect Immun 2002;70:3673-3680

52. Troeger $\mathrm{H}$, Epple HJ, Schneider $\mathrm{T}$, et al. Effect of chronic Giardia lamblia infection on epithelial transport and barrier function in human duodenum. Gut 2007;56:328-335. 
53. Crane JK, McNamara BP, Donnenberg MS. Role of EspF in host cel death induced by enteropathogenic Escherichia coli. Cell Microbiol 2001:3:197-211.

54. Nougayrede JP, Donnenberg MS. Enteropathogenic Escherichia coli EspF is targeted to mitochondria and is required to initiate the mitochondrial death pathway. Cell Microbiol 2004;6:1097-1111.

55. Flynn AN, Buret AG. Caspases-3, -8 and -9 are required for induction of epithelial cell apoptosis by enteropathogenic $E$. coli but are dispensable for increased paracellular permeability. Microb Pathog 2008;44:311-319.

56. Viswanathan VK, Weflen AW, Koutsouris A, et al. Enteropathogenic E. coli-induced barrier function alteration is not a consequence of host cell apoptosis. Am J Physiol Gastrointest Liver Physiol 2008;20:20.

57. Savkovic SD, Koutsouris A, Hecht G. Attachment of a noninvasive enteric pathogen, enteropathogenic Escherichia coli, to cultured human intestinal epithelial monolayers induces transmigration of neutrophils. Infect Immun 1996;64:4480-4487.

58. Savkovic SD, Koutsouris A, Hecht G. Activation of NF-kappaB in intestinal epithelial cells by enteropathogenic Escherichia coli. Am J Physiol 1997;273:C1160-C1167.

59. Zhou X, Giron JA, Torres AG, et al. Flagellin of enteropathogenic Escherichia coli stimulates interleukin-8 production in T84 cells. Infect Immun 2003;71:2120-2129.

60. Sharma R, Tesfay S, Tomson FL, et al. Balance of bacterial pro- and antiinflammatory mediators dictates net effect of enteropathogenic Escherichia coli on intestinal epithelial cells. Am J Physiol Gastrointest Liver Physiol 2006;290:G685-G694.

61. Savkovic SD, Koutsouris A, Hecht G. PKC zeta participates in activation of inflammatory response induced by enteropathogenic $E$. coli. Am J Physiol Cell Physiol 2003;285:C512-C521.

62. Savkovic SD, Ramaswamy A, Koutsouris A, et al. EPEC-activated ERK1/2 participate in inflammatory response but not tight junction barrier disruption. Am J Physiol Gastrointest Liver Physiol 2001;281: G890-G898.

63. Vallance BA, Finlay BB. Exploitation of host cells by enteropathogenic Escherichia coli. Proc Natl Acad Sci USA 2000;97:8799-8806.

64. Madara JL, Patapoff TW, Gillece-Castro B, et al. 5'-adenosine monophosphate is the neutrophil-derived paracrine factor that elicits chloride secretion from T84 intestinal epithelial cell monolayers. J Clin Invest 1993;91:2320-2325.

65. Crane JK, Shulgina I, Naeher TM. Ecto-5'-nucleotidase and intestinal ion secretion by enteropathogenic Escherichia coli. Purinergic Signal 2007;3:233-246.

66. Crane JK, Olson RA, Jones HM, et al. Release of ATP during host cell killing by enteropathogenic $E$. coli and its role as a secretory mediator. Am J Physiol Gastrointest Liver Physiol 2002;283:G74-G86.

67. Bruewer $M$, Luegering $A$, Kucharzik $T$, et al. Proinflammatory cytokines disrupt epithelial barrier function by apoptosis-independent mechanisms. J Immunol 2003;171:6164-6172.

68. Bruewer $M$, Utech $M$, Ivanov $A$, et al. Interferon-gamma induces internalization of epithelial tight junction proteins via a macropinocytosis-like process. FASEB J 2005;19:923-933.

69. Utech M, Ivanov Al, Samarin SN, et al. Mechanism of IFN-gammainduced endocytosis of tight junction proteins: myosin II-dependent vacuolarization of the apical plasma membrane. Mol Biol Cell 2005; 16:5040-5052.

70. Al-Sadi RM, Ma TY. IL-1beta causes an increase in intestinal epithelial tight junction permeability. J Immunol 2007;178: 4641-4649.

71. Guttman JA, Samji FN, Li Y, et al. Evidence that tight junctions are disrupted due to intimate bacterial contact and not inflammation during attaching and effacing pathogen infection in vivo. Infect Immun 2006;74:6075-6084. 